\title{
Demographics and Medical CaRe SPENding: STANDARD AND NON-STANDARD EFFECTS
}

\author{
David M. Cutler \\ Harvard University and National Bureau of Economic Research \\ Cambridge MA 02138 \\ Louise Sheiner \\ Board of Governors of the Federal Reserve System \\ Stop 83 \\ Washington DC 20551
}

April 1999

We are grateful to Srikanth Kadiyala for research assistance, and the National Institute on Aging for research support. We thank our discussants Victor Fuchs and Paul Gertler for very insightful comments. The views expressed in this paper are not necessarily those of the staff or members of the Board of Governors of the Federal Reserve System. 


\begin{abstract}
In this paper, we examine the effects of likely demographic changes on medical spending for the elderly. Standard forecasts highlight the potential for greater life expectancy to increase costs: medical costs generally increase with age, and greater life expectancy means that more of the elderly will be in the older age groups. Two factors work in the other direction, however. First, increases in life expectancy mean that a smaller share of the elderly will be in the last year of life, when medical costs generally are very high. Furthermore, more of the elderly will be dying at older ages, and end-of-life costs typically decline with age at death. Second, disability rates among the surviving population have been declining in recent years by 0.5 to 1.5 percent annually. Reductions in disability, if sustained, will also reduce medical spending. Thus, changes in disability and mortality should, on net, reduce average medical spending on the elderly. However, these effects are not as large as the projected increase in medical spending stemming from increases in overall medical costs. Technological change in medicine at anywhere near its historic rate would still result in a substantial public sector burden for medical costs.
\end{abstract}


It is a truism that demographic change will have major effects on the medical sector. Older people spend more on medical care than younger people, and the population will become increasingly aged over time. The share of the population over age 65 , for example, is expected to nearly doubly by 2050 , and the share of the population over age 85 is expected to more than triple. Even making the unrealistic assumption that medical costs increase at the rate of GDP, the increased age of the population alone will cause Medicare spending to nearly double as a share of the economy by 2050 and government nursing home spending to triple.

But a moment's thought demonstrates the difficulties with these conclusions. Clearly, medical spending rises with age. But why? Partly, the reason is that disability rises with age, and people who are disabled use more medical resources than people who are not disabled. If we are interested in understanding how demographic change will affect medical spending, therefore, we need to forecast the rate of disability in the economy. The simple projection described above assumed disability rates were constant by age, but substantial recent evidence (see Manton et al., 1997, and references cited there) suggests that disability rates have been falling over time and are likely to continue falling in the future. Certainly, people are living longer than they used to, and thus fewer people at any one time will be in the position of requiring high-tech, high-cost end of life care.

Medical spending also depends on the age and sex distribution of the population. People living with others are less likely to enter a nursing home than people living alone. Thus, medical spending in the future will depend on marriage rates among the elderly, the number of male and female elderly, and relationships between children and their parents. This too needs to be understood.

And on top of these demographic changes are forecasts for increasing medical care costs 
holding constant health status. Growth of per person medical care costs at anywhere near its historical rate -- nearly 2.5 percentage points about GDP growth -- would send public medical costs through the roof. Of course, the increase in per person medical spending that we have witnessed is not an immutable law of nature. It is driven by technological change in medicine and depends on the rate of progress in medical technology, and how technologies are utilized.

The coming demographic change may well lead to increases in medical spending in the future, but the simple analysis commonly used to evaluate this question is not adequate to evaluate its magnitude or consider policy alternatives.

In this paper, we examine the link between demographic change and medical spending, and consider the implications of different policies to limit the fiscal consequences of aging. We show that demographic change will almost certainly lead to major increases in public spending on medical care, but the link is nowhere near as clear as conventional wisdom suggests. We begin with a simple decomposition. Average medical spending depends on the number of people of each age and average medical care utilization at each age. The age distribution of the population is largely determined by fertility and mortality rates, ${ }^{1}$ and forecast changes in fertility and mortality clearly imply increased medical spending over time. The burden is further exacerbated because a smaller share of people will be working and paying taxes in the future, thus reducing the public revenues available to pay for increased medical costs.

Medical spending by age is more complicated, however, but also more important, since changes in age-specific medical spending have a substantively greater impact on future medical costs than do changes in the age distribution of the population. Forecasting age-specific medical spending is difficult. We consider first spending on acute medical care. We show that acute care medical 
spending can be explained well by disability and proximity to death; once these factors are taken into account, age itself has a rather small effect. People use more services when they are disabled and in the period just before death. Since disability and death rates are falling, relative medical spending by age will likely flatten over time. Offsetting this, however, is the increase in spending for any level of disability and time until death. Over time, society spends more on a given health state than it did in the past. Forecasting the rate of this technological change is crucial, but not well known. We present a range of arguments consistent with a more and less rapid growth of health-specific spending in the future than in the recent past.

We then turn to long-term care. While long-term care spending is small for the nation as a whole, it is large for the public sector; about $10 \%$ percent of public medical spending is devoted to nursing home care. Many of the same issues are relevant for long-term care as for acute care. As disability declines and people are farther away from death, the need for long-term care will fall. This will be offset by increased costs conditional on using services. But there is another important effect as well: the demand for formal long-term care depends on the availability of informal care (Lakdawalla and Philipson, 1998). Our analysis, however, shows that the availability of informal care is not likely to rise much--while mortality reductions mean that there will be fewer widowed spouses, the projections indicate that never having been married will also increase, leaving these elderly without spouses or children to care for them. If these projections are correct, then on net, the availability of informal care will not change much.

On net, our results confirm the conventional wisdom - medical spending will almost certainly become more difficult to afford in the future. But many of the factors we identify will have important implications for the magnitude of the spending increase, and for optimal policy design. 
We use our results to briefly remark upon policy options for medical care reform. Unlike in the case of Social Security reform, we do not find a large effect of potential increases in the age of eligibility on the long-term ability to finance medical spending. This is partly because the oldest old spend much more on medical care than the youngest old, so that cutting off the youngest old from receiving benefits saves much less than the share of the young elderly in the elderly population, and partly because if the eligibility age is raised, many more people will likely qualify for Medicare under disability rules. Since medical spending is so skewed to high spenders, having even a fraction of the high spenders remain on the public roles would eliminate much of the savings from increasing the eligibility age. We suggest instead that policy will need to focus on the management of medical care costs overall more than the distribution of costs among different participants.

The paper is structured as follows. In the first section, we review basic factors affecting medical spending over time: demographic change and per person medical costs. In the second section, we consider trends in the health of the elderly. We show that by essentially all measures, the elderly are healthier than they used to be. The third and fourth sections then examines the factors predicting changes in acute medical spending and long-term care spending in the future. The fifth section considers potential policy responses to demographic change. The last section concludes.

\section{A Framework for Analysis}

We start off with a basic framework for evaluating the role of demographic change in affecting medical spending. We denote the number of people in age group $a$ in year $t$ as $N_{a}(t)$. The average health status of people in age group $a$ in year $t$ is $h_{a}(t)$, and average medical spending 
conditional on health status is $m_{a}(t)$. For the population, medical spending is therefore:

$$
\text { Medical Spending (t) }=\sum_{a} m_{a}(t) \cdot h_{a}(t) \cdot N_{a}(t)
$$

In equation (1), medical spending may be total medical costs, in which case this is spending for the population as a whole, or it may be spending by the public sector, in which it is per person public medical spending. We focus particularly on public spending through Medicare and Medicaid.

Each of the three factors in medical spending - spending conditional on health, the average health of different age groups, and the age distribution of the population, will change over time. Table 1 shows information about population change through the middle of the next century. The elderly currently represent about 12 percent of the population. According to Social Security projections -- used also by the actuaries of the Medicare Trust Funds -- this share is expected to almost double by 2050, to 21 percent of the population. Even under the low, or optimistic, scenario, the share of the population that is elderly increases to 17 percent. The high, or pessimistic scenario, which many researchers have identified as more likely than the intermediate scenario, has an elderly share of the population of 26 percent in 2050 .

Furthermore, the average age of the elderly is increasing, as the ranks of the oldest old (those 85 and over, for example) are growing the fastest. Indeed, as Table 1 shows, under the intermediate assumptions, the population aged 85 and over more than triples--going from just 1.3 percent of the population in 1990 to about 4 percent in 2050 .

Forecasting the first two terms - average medical spending conditional on health status, and the average health of the population, is more difficult. The first term, expenditures given health 
status, depends on relative prices, relative intensity of treatment, and the state of medical technology. The second term is related to the needs of the population.

\section{Official HCFA Projections.}

Actuaries at the Health Care Financing Administration (HCFA) forecast Medicare spending for the Board of Trustees of the Federal Hospital Insurance (Medicare Part A, or inpatient services) and the Federal Supplementary Medical Insurance (Medicare Part B, or outpatient services) Trust Funds. The trustees issue a report on the financial health of the trust funds each year. In their most recent reports, they make the following assumptions:

Expenditures given health status. In the short run, HCFA uses recent trends in Medicare spending and legislative changes enacted in the Balanced Budget Act of 1997 to forecast the growth of spending given health status. Over the longer run, they assume that spending growth, given health status, stabilizes. In particular, they assume that for Medicare Part A, spending per unit of service grows at the rate of average hourly earnings. For Part B, they assume that spending per enrollee grows at the rate of per capita GDP. ${ }^{2}$

Figure 1 shows the difficulty of this projection. The figure shows the growth rate of real medical spending in different decades from 1929 to the present. ${ }^{3}$ Growth rates were relatively low in the pre-World War II era, increased rapidly from 1950 through 1990, and then slowed in the 1990s. On average, medical spending growth has exceeded income growth by 2.5 percent per year, although the gap has been much smaller (1.0 percentage points in the 1990s) as well as much larger (4.0 percentage points in the 1960s). 
Health status of the population. HCFA does not explicitly forecast the health of the population, but does so implicitly. For Part A services, the actuaries assume that health needs are constant across age and sex. This effectively means that medical needs change only as the population changes.

The right panel of table 1 shows the consequences of this assumption. Medical spending is highly skewed to older ages. The average person over age 65 spends 3.5 times as much on medical care as the average working age person. And the oldest elderly (ages 85+) spend 6 times the amount of the working age population. As the last column shows, the disparity is even greater for public medical spending. Thanks to generous Medicare and Medicaid benefits, the average elderly person spends more than 8.5 times more of public dollars on medical care than the average working age population. The ratio is $14: 1$ for the oldest elderly.

For Part B, the actuaries assume that needs are constant over time (i.e., without even any adjustment for age and sex composition changes.) This is somewhat puzzling, since outpatient service use does increase with age. Within the current framework, adding an adjustment for differential service use by age seems natural.

Figure 2 presents projections of Medicare spending using the Trustees' projections. The upper panel shows the growth of total real Medicare spending; the lower panel shows Medicare as a share of GDP. The Trustees forecast that Medicare spending will rise from its current 2.5 percent of GDP to nearly 6.5 percent of GDP by the middle of the next century.

The projections assume a reduction in Medicare spending growth over the next few years, stemming from the provisions of the Balanced Budget Act of 1997, which cut Medicare substantially in the short term. After the turn of the century, growth in Medicare spending is forecast to increase, 
to about 3 percent in real terms per enrollee. This higher growth rate continues until 2020. After that year, Medicare spending stabilizes as a share of the economy. This is a direct result of the assumption that spending per enrollee increases at the rate of wage growth (Part A) or GDP growth (Part B).

\section{The Health of the Elderly}

As noted above, a crucial issue in forecasting medical spending is forecasting changes in the health of the population. The most important health issues affecting medical spending are for the elderly. Before considering alternative projections, we first discuss evidence on trends in the health of the elderly population.

The starting point in evaluating health for the elderly is the decline in mortality over time. An individual born in 1960 and facing the cross-section mortality profile that year had a 71 percent chance of reaching age $65 ;^{4}$ the same person born in 1990 and facing the 1990 mortality profile had a 90 percent chance of reaching age 65 . Changes in mortality within the elderly population have been even more dramatic. A person reaching age 65 in 1960 had a 26 percent chance of surviving to age 85 . The same person in 1990 had a 38 percent chance of surviving to age 85 .

Table 2 shows the magnitude of survival improvements another way. We calculate the share of "marginal" survivors in 1990 in comparison to 1960,1970 , and 1980. The first column of the table, for example, shows the share of the $65+$ population alive in 1990 who would not have been alive under the mortality rates prevailing in 1960,1970 , or 1980 . The share of marginal survivors ranges from 6 percent in relation to 1980 to 23 percent in relation to 1960 . As the second through 
fourth columns show, the share of marginal survivors is substantially greater at older ages. Half of the population aged 85 and older that was alive in 1990 would not have been alive under the mortality structure prevailing in 1960.

The period just before death is generally one of high disability. Medicare spending, for example, is 7 times greater for those in the last year of life than for those who are not in the last year of life (Lubitz and Riley, 1993). ${ }^{5}$ As the population lives longer, changes in the share of people in the last year of life will change disability rates. Table 3 reports the probabilities that a person is in the last year of life between 1990 and 2070 based on Social Security mortality assumptions. For each age group, the probability of being in the last year of life declines substantially over the projection horizon. Among people aged $85-89$, for example, the probability of dying within a year falls from 11.5 percent to 7.9 percent, a one-third reduction.

For Medicare as a whole, however, the changes are more muted. When younger people do not die, they become older people, where the probability of death is greater. Between 1990 and 2030, the percentage of all Medicare beneficiaries in their last year of life declines from about 5 percent to 4.2 percent. After 2030, the fraction of Medicare beneficiaries in their last year of life begins to climb again, as the baby boom population moves into their $80 \mathrm{~s}$ and $90 \mathrm{~s}$.

Increasing longevity may have other effects on health of the elderly population, however, beyond its implications for the share of people near death. ${ }^{6}$ The increasing importance of marginal survivors at older ages has lead some to predict that the health of the surviving population is worse. Suppose, for example, that treatment for people who have had a stroke improves, so that more people survive a stroke than did in the past. This would increase the share of marginal survivors in the population but create additional medical needs for those alive. Stroke survivors need acute services, 
rehabilitation care, and frequently long-term care as well. If there are more marginal stroke survivors with high medical needs, the health of the living population would, on average, decline, even as longevity improves.

But there are other scenarios about the relation between longevity and medical care needs. To use the stroke example, one alternate scenario is that the incidence of strokes is falling over time, so more people are surviving to older ages without any debilitating condition. In the case of cardiovascular disease, better prescription drugs (such as anti-hypertensives) and improved behavioral factors (better exercise, reduced smoking, reduced salt intake) have all reduced the risk of a major cardiovascular disease incident. Estrogen replacement therapy and increased attentiveness to physical surroundings may reduce the risk of hip fractures.

Health may also improve because we are better at caring for people after disease, so that those who survive are in better health. The improvement in health among those who would have survived the disease in all time periods may then outweigh any reductions in health from more marginal survivors. Changes in medical practice have almost certainly had this effect. In the case of cardiovascular disease, thrombolytic therapy delivered soon after an acute incident dramatically reduces the adverse consequences. Thrombolytic therapy was unknown in 1960 but was used commonly in 1990. Improvements in physical or occupational therapy have the same effect: they improve the health of survivors. And behavioral factors such as reduced salt and anti-hypertensive therapy, even as they prevent cardiovascular illness, also reduce its adverse consequences when it occurs.

Whether, on net, increases in longevity are associated with improvements or reductions in average health is therefore an empirical question. We present evidence on this question here, 
although readers interested in more detail might examine a wealth of recent papers (for example, Manton et al., 1997; Hoffman et al., 1996; Vita et al., 1998; Fries et al., 1993). Some first evidence on this question is provided by considering the recent history of mortality reduction. As figure 3 shows, the dominant source of improved longevity in the past 30 years has been reductions in cardiovascular disease mortality -- coronary heart disease and cerebrovascular disease (stroke). Mortality from these sources has fallen nearly 3 percent annually since the late 1960s.

Several papers have analyzed the sources of the reduction in coronary heart disease (CHD) mortality, a major source of cardiovascular disease death. Roughly one-third of the reduction in CHD mortality is attributable to reduced incidence of CHD (termed primary prevention). CHD incidence has fallen about 1 percent per year in the past three decades (Sytkowski et al., 1990; Sempos et al., 1988; Hunink et al., 1997). Declines in disease incidence are almost certainly associated with increases in the average health of the surviving elderly population.

Survival after a CHD incident accounts for the remaining two-thirds of the improvement in CHD mortality. Increased survival after CHD is partly a result of improved acute treatment (for example bypass surgery) and partly a result of better post-acute treatment (termed secondary prevention). Secondary prevention is generally behavioral changes (reduced smoking, better exercise, reduced salt intake) and prescription drugs (anti-hypertensives, anti-lipidemics) that prevent long-term coronary damage and a re-emergence of a serious incident. The role of acute treatment and secondary prevention in improved health likely varies over time. Older literature examining changes in CHD mortality in the late 1960s and 1970s found that secondary prevention was more important than acute treatment (Goldman et al., 1984), but more recent studies from the 1980s place more weight on intensive treatments (Hunink et al., 1997). 
In all time periods, though, at least one-half, and perhaps as much as three-quarters of the health improvement are a result of primary and secondary prevention, rather than advances in hightech medicine. Increased prevention, both primary and secondary, almost certainly results in better health among the surviving population. Given the dominance of these factors in explaining improved health, we suspect that reduced mortality has not been accompanied by a less healthy surviving population.

There is some empirical data to back this up. Measuring "health," of course, is quite difficult, since health is a multi-attribute concept, with both physical and mental dimensions. As a result, there is no one summary measure that one can look at to examine changes in health. We therefore examine several measures of health among the elderly. ${ }^{7}$

Table 3 shows a first measure of health - how many restricted activity days or bed days a person had in the previous year. Data on restricted activity days are available in the National Health Interview Surveys (NHIS) since 1969. We examine restricted activity days at five year intervals $(1970,1975,1980,1985,1990$, and 1995). Because the sample sizes for some of the demographic groups are small (particularly the oldest old), we pool three years of data for each estimate. For example, data for 1970 are formed by pooling data in the 1969,1970 , and 1971 surveys. $^{8}$

We report restricted activity days and bed days for the elderly population as a whole, and for the population in different age groups. In each case, the data are standardized by age and sex. For example, the estimate of restricted activity days for 65-74 year-olds is a weighted average of the rates for 65-69 year-old men and women and 70-74 year-old men and women. ${ }^{9}$

The average number of restricted activity days for the elderly is relatively high: about 30 to 40 per year. The oldest elderly have more restricted activity days than the younger elderly, but not 
by a very large amount. Examining the data over time shows a clear pattern. Over the 1970s, restricted activity days increased. For the elderly as a whole, restricted activity days rose from an average of 33.1 in 1970 to 40.7 in 1980 , or 2.0 percent annually. This is true for each subgroup of the population.

This increase in restricted activity days was taken by many to be a sign that marginal survivors were reducing the health of the elderly population (for example, Crimmins, 1997). Some discussion in the early 1980 s highlighted the difficult burdens this increase in the share of marginal survivors was likely to have for Medicare, and for society. But others saw the change as a reporting phenomenon; people may have reported themselves in worse health but underlying health might not change or even improve (Waidmann, Bound, and Schoenbaum,1995). One reason for this is that disability is a qualification element for several public programs, such as disability insurance or Supplemental Security Income. In addition, people might report more disability because they have been diagnosed with more diseases. A person with scattered aches and pains may not report themselves as restricted in activity if they know that all elderly feel similarly. But when doctors label the condition (for example, rheumatoid arthritis), people may come to believe they are restricted in activity because of a medical condition. ${ }^{10}$

This debate has been muted by the experience of the 1980s and 1990s, however. Since 1980 , restricted activity days have fallen, by 1.3 percent per year on average. The decline was for all age groups. Whatever one believes about the 1970s, therefore, the clear conclusion since 1980 clearly suggests health improvements among the elderly.

The bottom rows of the table show trends in days in bed. Bed days rose from 1970 through 1985 , at an annual rate of 0.5 percent. Since 1985 , bed days have fallen by 0.8 percent per year. 
Again, the decline is common for all age groups. Unlike with restricted activity days, bed days declined rapidly in each of the two five year intervals.

Table 5 examines whether the elderly can engage in "major activities" - defined as working, keeping house, school, something else, or unknown. People are asked to categorize themselves as: unable to perform their major activity; limited in the kind or amount of the major activity; limited in other activities but not their major activity; or not limited. Consistent data on this question are available since 1982. About 40 percent of the elderly have some limitations in activities, although for only 10 percent of the elderly does it prohibit them from performing their major activity. The share of the elderly limited in their major activity fell between 1985 and 1995, but the decline has been relatively modest -- 0.4 percent overall, and 0.2 percent per year for those prohibited from performing their major activity. The declines are present for each of the age groups.

In addition to physical health, we also want to know about mental health. Unfortunately, the NHIS does not ask about mental cognition. But the survey does ask people to self-rate their health. Presumably, people consider their mental as well as physical health in answering such questions. Table 6 tabulates self-reported health of the elderly. Prior to 1982, the choices were excellent; good; fair; or poor. After 1982, very good was added as an additional category. Because of this change, the share of people in excellent, very good, or good health cannot be reliably compared over time. But the share of people in fair or poor health can be determined. As the table shows, the share of people in fair or poor health has declined uniformly since the 1975 . In 1975, 32 percent of the elderly were in fair or poor health; by 1995 , the share was 28 percent, for a 0.7 percent annual decline. The decline in the share of people in fair or good health has only occurred for the younger elderly population. The share in both fair and poor health has increased for the population aged 85 
and older.

A separate way to measure disability is to measure specific physical functions. Researchers have identified two types of impairments that indicate directly people's physical and mental activity: impairments in activities of daily living (ADLs), such as the ability to walk, dress, and bathe oneself; and impairments in instrumental activities of daily living (IADLs), such as the ability to cook, clean, or manage money. The National Long Term Care Survey (NLTCS) has measured the rate of impairments in ADLs and IADLs since the early 1980s.

Table 7 shows changes in disability rates from this survey (taken from Manton, et al., 1997). Disability fell substantially from 1982 through 1994, at a 1.3 percent annual rate. The decline in disability is more significant for the greatest levels of disability. Institutionalization rates, for example, fell by 1.6 percent annually, and the rate of very severe disability in the community (5-6 ADLs) fell by 2.1 percent annually. The decline in disability also appears to have increased over time. The rate of disability decline was 1.3 percent between 1984 and 1989 , and 1.8 percent between 1989 and 1994.

The evidence that disability rates were declining in the United States spurred efforts to examine this issue in other countries. Table 8 shows evidence on disability rates in other developed countries. The first columns of the table show severe disability rates (usually 3 or more impairments in activities of daily living). The second columns of the table show institutionalization rates. In most countries, disability rate have been declining over time. The decline is only modest in some countries (for example, the UK) but is rapid in others (for example, Japan). The average rate of decline among countries where disability rates are falling is 2.3 percent per year. In only two countries do rates of severe disability increase (Australia and Canada), but in each of these countries, 
the institutionalization rate is falling.

Institutionalization rates have been falling as well in 4 of the 5 countries for which there is time series data. The decline is generally less rapid than the decline in the rate of severe disability. The one exception is France, where institutionalization rates have been increasing. But this may just be a change in the location of care; rates of severe disability in France are declining rapidly.

In total, the evidence suggests clearly that for the past 15 to 20 years, the health of the surviving elderly has improved. Prior to that time, there is more debate about what was happening to health.

In forecasting health status, we care not just about changes in the health of the elderly, but also about why health is improving. If disability declines are a result of increased medical spending, one would not want to forecast a reduction in medical spending resulting from declining disability without also factoring in the increase in medical care costs needed to produce the disability decline.

Over the span of the past few centuries, it is clear that high-tech medicine has not been the most important factor contributing to reduced disability. Factors such as income and nutrition (Fogel, 1994; McKeown, 1976), lifestyle changes, technology such as refrigeration (Manton et al., 1997), and public health (Preston, 1996), have been far more important than medical care in increasing longevity. These factors do not require expensive medical interventions to achieve. More recent evidence, however, assigns a much greater role to high-tech medical interventions in improved health, at least as regards coronary heart disease. This argues that future improvements in health might require additional medical spending.

How much disability reduction in the past depended on medical spending, and to what extent it will in the future, are open questions. Researchers have not yet focused on the reasons for the 
reduction in disability, although Manton et al. (1997) speculate that reduced disability is more attributable to factors such as the spread of aspirin after a cardiovascular disease illness or estrogen replacement therapy for elderly women than to expensive medical interventions.

The potential for future reductions in risk factors, and thus reduced disability, is certainly large. Smoking rates are still high, particularly among the less educated, rates of obesity have been increasing, and high cholesterol is prevalent. In addition, many low cost medical interventions -such as beta blockers after a heart attack -- have not diffused widely. Thus, one scenario is that we will learn even more about medical risks, and the spread of knowledge about risk factors will lead to substantial disability reductions. An alternate scenario, however, is that the marginal product of risk factor reduction declines, leading to a reduction in the "exogenous" component of disability decline. We consider both scenarios in our spending forecasts.

\section{Forecasting Acute Care Medicare Spending}

In this section, we examine how changes in disability and per person medical spending will affect Medicare spending on acute care services in the future.

Changes in the Age of Death. The first factor affecting medical spending is the increasing age of death. Increases in the age of death will have two effects on Medicare spending. First, fewer people will be in the last year of life and, as noted above, people in the last year of life spend more on medical care than those further away from death. Thus, increases in the average age of death will increase the average healthiness of the population, and thus reduce Medicare spending. 
In addition, analysts have also noted another feature of Medicare spending--the older the beneficiary, the less Medicare spends in the last year of life (Lubitz, Beebe, and Baker, 1995). Table 9 shows data on spending in the last year of life, taken from Lubitz and Riley (1993). Spending in the last year of life averages about $\$ 15,500$ for the young elderly - those aged 65-74. Average spending then falls to about $\$ 13,000$ for those aged $80-84$, and declines to below $\$ 9,000$ for those aged 90 and older. Spending among survivors, in contrast, is much more constant by age.

The reason for the change in end of life spending as people age is not entirely clear. It may be that providers are less likely to use aggressive medical technology on the very old. Alternatively, the very old might be more likely to die from "natural causes" than from debilitating disease. But assuming that this trend continues, the gradual increase in the average age at death implicit in the Social Security assumptions means that costs associated with dying will decrease.

As the average age of death increases, and as the health of the elderly increases, it is possible that the oldest old will be treated more aggressively in the future than in the past -- muting if not eliminating this source of savings. For example, if 90 year-olds are not considered particularly infirm in the future, doctors may be more likely to use invasive technologies on this group than they might have been in the past.

Substantial changes in the distribution of medical spending by age have occurred in the past few decades. Cutler and Meara (1998) show that between 1963 and 1987, medical spending among the over 65 population rose by 8 percent per year in real, per person terms, compared to 5 percent for the population aged 1-64."

Changes in the age distribution of medical spending within the elderly population are more subtle. Table 10 shows the growth of real Medicare spending per person for different ages. Between 
1967 and 1977, medical spending growth was more rapid for the younger elderly population than for the older elderly population. In the subsequent decade (1977-87), spending growth was relatively constant by age group, and in the following eight years (1987-95), growth rates were much greater for the older elderly population than for the younger elderly population. ${ }^{12}$ This pattern is somewhat different than for medical spending as a whole, measured in repeated national medical expenditure surveys. Cutler and Meara (1998) show that medical spending growth from 1963-70 and again from 1970-77 was greater for the older elderly population than for the younger elderly population. It may be that out-of-pocket costs rose more rapidly for the older elderly than did Medicare costs.

Data on the share of Medicare spending in the last year of life suggest little change in this relationship over time. Lubitz and Riley (1993) show that payments for elderly Medicare beneficiaries in the last year of life represented 28.2 percent of Medicare payments in 1976, 30.8 percent in 1980, 27.4 percent in 1985 and 28.6 percent in 1988. In the absence of firm data about how Medicare cost growth will differ by age or time until death in the future, we assume that growth will be the same over time.

Table 11 shows how average Medicare spending per beneficiary will change with changes in the age of death. The first row of the Table shows spending assuming a constant profile of spending by age. This is the assumption that the Medicare Trustees make in their current projections (at least for inpatient spending). To focus on the health status issues exclusively, we assume no growth of real spending per person. As the population ages, projected spending rises, by 3 percent in 2010 and 9 percent in 2050 .

The next rows of the table show alternative projections accounting for increases in the age of death. In this scenario spending per person falls over time. Even though the average age of the 
elderly population is higher, fewer people are in the last year of life and people who are in the last year of life are older, and thus spend less. By 2010, costs are about 2 percent lower than they would be if mortality remained constant, and by 2050 they are 6 percent lower. The reductions in cost are roughly constant across age groups.

Changes in Disability Rates Among Survivors In addition to reduced disability because fewer people are near death, there may also be reduced disability among survivors. As noted above, disability rates have declined over time, at anywhere from 0.5 percent to 1.5 percent per year, depending on the measure and time period. An appropriate projection would account for continued changes in disability rates as well.

To examine the impact of potential changes in disability, we need to determine how much more care people with disabilities use than those without disabilities. Table 12 presents the results from a regression of Medicare expenditures on age and disability. We use data from the 1992 Medicare Current Beneficiary Survey. Since we have accounted for decedents separately, we include only those who did not die in either 1992 or $1993 . .^{13}$

The first column of the table shows average Medicare spending for survivors by age. Cost for the young elderly are about $\$ 1,850$ per person. For the oldest elderly (ages 85 and older), costs are an additional $\$ 1,700$ higher per year. The second column includes the number of ADL and IADL impairments for the individual. The number of impairments is measured in the last quarter of 1991, before any of the Medicare spending. Thus, problems of reverse causality between sickness, spending, and impairments are avoided. ${ }^{14}$ The regressions show that a large part of the relationship between health costs and age is better attributable to the relationship between disability and age. 
Once disability is accounted for, the relationship between health expenditures and age is much weaker. For example, two-thirds of the effect of being over age 85 is accounted for by disability instead of age. Indeed, medical spending for survivors, holding constant the level of disability, actually declines from ages 80-84 to ages $85+$. The ADL and IADL coefficients, in contrast, are large. Every additional ADL increases average spending by $\$ 250$ per year, and each additional IADL increases average spending by nearly $\$ 500$ per year.

We use these results to simulate what would happen to survivor costs were disability to continue declining in the future. As a benchmark forecast, we assume that the average level of ADLs and IADLs will decline by $1 \%$ per year (forever). The regressions in table 12 translate these changes into average spending per beneficiary. We then add our projections of Medicare expenditures in the last year of life to get an estimate of average Medicare expenses, per beneficiary, arising from changes in mortality and disability.

The third panel of table 11 shows these projections. Reductions in disability rates of 1 percent annually along with the increase in age at death would have a very large effect on Medicare spending. Average spending per person would decline by 3 percent by 2010 and by 13 percent by 2070. Recall that the naive forecast, holding constant age-specific disability rates, is for a 9 percent increase in spending by 2070 , so that changes in health would have a cumulative effect of 22 percent on per beneficiary spending on medical care. As the next row shows, if disability declines for survivors were 1.5 percent per year, average spending would be 16 percent lower by 2050 .

Changes in Disability-Specific Spending. The third factor influencing costs is changes in spending per level of health -- the first term in equation (1). Forecasting the rate of increase in 
disability-specific Medicare spending is hazardous. Five decades ago, when medical spending was 5 percent of GDP but beginning to rise, it was commonly assumed it would not reach 10 percent. But spending did. Two decades ago, when medical spending was 10 percent of GDP, it was commonly thought that spending could not reach 15 percent of GDP. It has. Today, it is common to assume that medical spending cannot continue to increase indefinitely at its current rate, as the Medicare Trustees do. But, of course, there is no reason it cannot.

More fundamentally, the question is not whether medical spending per person will increase, but what drives medical spending. A voluminous recent literature has examined the sources of increase in medical costs over time (see Cutler and Sheiner, 1998, for a review). The uniform conclusion is that medical spending increases are driven by changes in medical technology. As technology has advanced, people can be treated in increasingly sophisticated ways, increasing length or quality of life but incurring substantial expense.

Thus, to address this question we need to forecast the rate of technological change in medicine. Difficult questions produce a multiplicity of answers, and this question is no exception. It is useful to think about this question by considering the process of disease treatment. ${ }^{15} \mathrm{~A}$ half century ago, most diseases were untreatable. We did not know what caused them, or what to do about them. Spending was low (although the morbidity costs of disease were high). As knowledge expands, the ability to treat disease improves. Initially, most treatments are curative - they treat people who have the disease, rather than prevent the disease from developing. An example is bypass surgery for heart attacks. Bypass surgery is designed to restore blood flow after a heart attack, not to prevent a heart attack from developing. Treating disease after it occurs is more expensive than not treating disease (although it may be a good use of money). The final stage is prevention. 
Prevention is typically cheaper than treatment on an average cost basis. For example, it is cheaper to give someone anti-hypertensive medication than to give the same person bypass surgery. But for the population as a whole, the cost issue is more difficult. Because prevention is generally given to many more people than treatment, the total costs of prevention may be greater. The additional spending on prevention, of course, may be worth the money.

Over the past half century, many diseases have moved from untreatable to curable after the fact. Not surprisingly, this has come at substantial expense. One argument about future spending is that even more diseases will move from untreatable to treatable. For example, Alzheimer's disease is largely untreatable now, but may be treatable (at very high cost) in the near future. Mapping the genetic sequence promises to expand our range of knowledge about disease tremendously, with potentially large implications for costs.

A separate argument, however, is that as we make more fundamental advances in medical knowledge, we will be able to prevent more diseases from occurring, and this may reduce costs. For example, better anti-hypertensive medication over time has almost certainly contributed to the substantial reduction in coronary heart disease incidents in recent decades. Cost-effectiveness analyses generally suggest that preventive care for CHD is far more cost-effective than ex post treatment (Garber and Phelps, 1997; Meltzer, 1997).

The structure of the medical system will also play some role in the rate and composition of technological change in medicine. In the era of traditional indemnity insurance, the incentives favored technology that improved health, even if only marginally and at great additional expense. In the new, managed care era, there may be more emphasis on technologies that either save money or do not involve such large expenses. The rate of application of new technologies may also be 
curtailed by managed care. Cutler and Sheiner (1998) find some evidence that technology diffusion has been slowed by managed care.

It is clear that any forecast of disability-specific medical care cost growth is perilous. Rather than make one assumption, we consider a number of alternatives. The first alternative, presented for convenience more than projection accuracy, is that real per person medical care costs will not increase over time. This is the assumption embedded in the first parts of table 11. Our second assumption is that medical spending increases in the future at the rate of GDP growth. This is consistent with the long-range assumptions made by the actuaries of the Medicare Trust Funds. The final assumption is that medical care costs increase by 2.5 percent more than GDP growth, the average additional rate of increase in the post-World War II period.

The last rows of Table 11 show average medical spending under these latter two assumptions (results based on the first assumption are already in the table). It is clear that increases in medical spending conditional on health status will have a substantial effect on overall Medicare costs. Even with the reduction in mortality and a 1 percent annual decline in disability, Medicare spending as a share of GDP would increase more than six-fold by 2050 .

Just as we are uncertain about the future course of disability, we are also uncertain about the average rate of medical spending increase over the next seventy-five years. The level of spending implied by the projections in table 11 is extremely large, particularly in relation to historical government budgets. Some fundamental change in the medical system or people's attitudes towards medical spending may occur before then.

Summary. Our results suggest that demographic and cost factors are both important in 
forecasts of acute care spending. A dominant role is clearly played by increasing costs per health state. But demographic change - most notably the potential for significant reductions in disability among the elderly and postponement in the age of death - are also important.

\section{Nursing Home Use and Expenditures}

A similar framework can be used to analyze the impact of changing demographics on nursing home use. Because nursing home use is much more common among the very old than among the younger aged, the aging of the population is expected to have a dramatic effect on nursing home use. But public attention to the nursing home problem has been much smaller. Only about $50 \%$ of nursing home costs are paid for by the public sector (mostly Medicaid), and these funds are financed out of general revenue. Hence, there is no Trust Fund insolvency issue to concentrate attention.

\section{The Determinants of Nursing Home Care}

In order to project future nursing home use, it is important to determine which factors are associated with nursing home use. Once again, nursing home use increases with age; but why? The health status of the individual is clearly important, but so are other socioeconomic factors, such as sex, race, marital status, number and location of children, income, wealth, etc. We particularly focus on variables that are likely to change in the future--age, disability, marital status, and proximity to death.

Table 13 reports regression results from the 1992 Medicare Beneficiary Survey on the use of nursing home care. The first set of columns are for men, and the second set are for women. The 
first column of each panel reports the results of a regression using only age group dummies as the independent variables. Nursing home use increases substantially with age, particularly for the 80-84 and $85+$ age groups. The increase in nursing home utilization as one ages is 10 percentage points for men and 25 percentage points for women. That difference, combined with the larger number of elderly women than men, implies that nursing home use is substantially concentrated among older women.

The second columns include marital status variables. Because nursing home use is so much higher for those 85 and over, we allow the coefficient on marital status to differ for that age group. As the coefficients indicate, being unmarried (widowed, divorced, or never married), increases nursing home use substantially, particularly for those age 85 and over. The data set we use does not contain good information on whether people have children; we suspect that the much larger effect on nursing home use of never having been married than of being widowed or divorced is a proxy for the lack of children. Controlling for marital status substantially reduces, but does not eliminate, the effect of age on nursing home utilization. Additional utilization for the very elderly in these regressions is 5 and 17 percent.

The third column adds the number of ADLs and IADLs to the regressions. Both measures of disability are important predictors of nursing home use. For women, the impact of ADLS and IADLS is substantially larger for those 85 and over than for those below age 85 . In general, including measures of disability reduces the impact of marital status on nursing home use. Indeed, for women, the effect of marital status in these regressions is generally not statistically significant.

The final columns include a variable for whether death is imminent -- within the next two years. ${ }^{16}$ Impending death has a large effect on nursing home utilization. For men, being near death 
raises nursing home use by about $4 \%$; for women, the effect is larger, about $8 \%$. Including proximity to death does not reduce the impact of ADLs and IADLs. Disability still has an important effect on nursing home utilization.

We use the regression coefficients to simulate nursing home use among the elderly in the future. The results are shown in table 14. The first row of the table shows future nursing home utilization assuming that rates of use remain constant by age and sex. This is the type of forecast that is most similar to current estimates of acute care spending in the Medicare Trust Funds. The effect of population aging is quite apparent. Average nursing home use increases between 1992 and 2010, reflecting the increasing share of those aged 85 and over in the elderly population. Between 2010 and 2030 , the share of those aged 85 and over actually declines, leading to a decline in nursing home use back to its 1992 level. The rate of use climbs again to roughly $7 \%$ by 2050 , and remains there.

The marital status of the elderly will change quite significantly over the next 50 years. Table 15 presents the Social Security Administration's marital status projections. Overall, marriage rates for men decline, by nearly 10 percentage points, while marriage rates for women rise, by about 6 percentage points. However, rates of marriage for those 85 and over increase both for men and women, as substantial declines in the rate of widowhood offset increases in the divorce rate. The fraction of the elderly who have never been married tends to increase over time.

We evaluate the importance of these changes in marital status using the regression coefficients presented above. The second panel of table 14 shows the results. All told, these patterns do not have a substantial effect on nursing home use, as increases in marriage (which would reduce nursing home use) are offset by increases in the fraction of people never married (and hence the fraction with no children to take care of them.) While the pattern varies over time, in general, 
changes in marital status slightly increase the likely rate of nursing home use.

The next panel shows the effect of a 1 percent annual reduction in disability rates on nursing home utilization. If the trend towards reduced disability continues, it will substantially reduce the demand for nursing home care. Rather than increasing to 7.1 percent by 2070 , including the effects of marriage and disability leads to the conclusion that disability declines would reduce nursing home use to roughly half that level, or 3.4 percent in 2070 . The reduction in nursing home utilization, relative to the first row in the table, is 71 percent. Even by 2010 , the difference is substantial. Of course, it is not clear whether the recent trend of decreasing disability among the elderly will continue--particularly over 75 years. But if it does, these numbers suggest that the impact on nursing home use would be quite substantial.

The next set of rows adds the effect of fewer elderly being near death, and thus facing the infirmities of end of life care. Including changes in the share of elderly near the end of life also lowers our projections of nursing home use, particularly in the out years. By 2050, nursing home utilization would decline by over 50 percent, in comparison to the 35 percent increase in utilization in the baseline forecast. It is clear that accurately forecasting nursing home use in the future requires assumptions about utilization before death and disability that traditionally have been very hard to infer.

Table 14 also shows the impact of these changes in the share of GDP accounted for by nursing home care. In the first four blocks of the table, we assume that the average price of nursing home care increases at the rate of GDP per capita. Assuming constant nursing home utilization by age and sex, the share of nursing home care in GDP will more than triple by 2050 . Under the most optimistic scenario, of decreasing death and disability, the share barely climbs at all--ending up in 
2070 only $20 \%$ above the level in 1992.

The last row of the table shows the important role that changes in the cost of a nursing home have on the estimates. Between 1965 and 1995, the cost of a day in nursing home increased by about 4 percent annually, in real terms. In the last row of the table, we forecast nursing home spending assuming this growth rate continues into the future. Under this scenario, nursing home costs increase from 1 percent of GDP in 1990 to 7.3 percent of GDP in 2050, even given the optimistic assumptions about mortality and disability.

Unlike in the case of acute care medicine, there is relatively little research on the factors explaining the growth in nursing home costs per day. Nursing home are less technologically sophisticated than are acute care hospitals, so one would imagine that technological change would have less of an effect on nursing home costs. But other factors, such as changes in the average sickness of the elderly in nursing homes, may be important. Understanding the reasons for the underlying growth in nursing home costs, as well as the likely future course of disability reductions and death, are important issues in medical forecasting.

\section{Policy Options for Medicare Reform}

Even under optimistic assumptions about reductions in disability and life extension, Medicare and Medicaid financing remains a significant burden for the public sector. Some reform of these programs will clearly be needed.

Current cost containment policies in these programs are not well designed for the long-term problems of the system. Over the past decade, cost reductions in Medicare and Medicaid have been 
achieved by reducing prices paid for services. For example, payments to hospitals for each admission have increased less rapidly than the growth of input prices would warrant. The same is true for payments to physicians. But as we noted above, the fundamental driver of medical care cost increases is increases in the quantity of services provided. Reductions in prices will never be sufficient to offset increases in the quantity of services over time.

Thus, some alternate form of cost reduction is necessary. We do not discuss reform options in great detail here, but do note a couple of issues for which our results have bearing. One common reform option is to increase the age of eligibility for Medicare benefits, along the lines of the scheduled increase in the Social Security normal retirement age. Our results suggest that the cost savings from such a policy would be smaller than for Social Security. There are two reasons for this. First, because medical costs increase with age, the young elderly use a smaller share of medical care services than the older elderly. As table 16 shows, 30 percent of the elderly population is between ages 65 and 69, but that group accounts for only 22 percent of Medicare resources. The disparity in Medicaid resources is even greater, since the young elderly are much less likely to be in a nursing home than the old elderly.

Second, increasing the age of eligibility will almost certainly be offset at least partly by increased Medicare eligibility through disability. ${ }^{17}$ Because medical care spending is so skewed -the top 10 percent of users aged 65-69 account for three-quarters of Medicare spending in that age group (see table 16) -- even a moderate offset of increased disability for the very sick would substantially reduce the potential savings from increasing the age of Medicare eligibility.

Perhaps more important will be efforts to reduce overall medical care spending for the elderly population. As noted above, technological change in medical care is a key determinant of the long- 
term growth of medical care costs. One might thus evaluate policies in terms of their long-term impact on the diffusion of medical technology. For example, Cutler and Sheiner (1998) show that increases in managed care enrollment over time have reduced the rate of growth of medical spending, in part by reducing the diffusion of high-cost medical technology. In light of these results, it may be that policy should focus on the management of medical care more than just the division of costs among different participants.

\section{Conclusion}

Medicare and Medicaid costs are extremely difficult to project. Expenditures in the future will depend on what happens to the underlying health of the elderly, what technologies will be available, and how the health care market is organized. In this paper, we have taken a first step in evaluating how improvements in the health of the elderly could affect medical spending. Our analysis suggests that changes in the underlying health of the population can be help restrain the growth of health care spending in the future, although they do not undo the effects of continued rapid growth in health costs. Our initial examination of Medicare spending over time suggests that there is no clear and consistent relationship between increases in overall health costs and changes in agespecific spending. Nonetheless, future technological advances could have differential effects on health spending by age group. We believe that this is an important topic for future research. 


\section{References}

Crimmins, Eileen M., Yasuhiko Saito, and Sandra L. Reynolds. 1997. "Further Evidence on Recent Trends in the Prevalence and Incidence of Disability Among Older Americans From Two Sources: The LSOA and the NHIS." Journal of Gerontology: Social Sciences 52B(2) S59-71.

Cutler, David and Ellen Meara. 1997. "The Medical Costs of the Young and Old: A Forty Year Perspective," in David Wise, ed., Frontiers in the Economics of Aging, Chicago: University of Chicago Press, 1998, 215-246.

Cutler, David and Louise Sheiner. 1997. "Managed Care and the Growth of Medical Expenditures", in Alan Garber, ed., Frontiers in Health Policy Research, Volume 1, Cambridge, MA: MIT Press, 1998, Chapter 3.

Fogel, Robert W. 1994. "Economic Growth, Population Theory, and Physiology: The Bearing of Long-Term Processes on the Making of Economic Policy" American Economic Review 84(3): 369395.

Fries, James F. 1989. “The Compression of Morbidity: Near of Far?” Milbank Quarterly 67:208-32.

Fries, James F., et al., "Reducing Health Care Costs By Reducing The Need And Demand For Medical Services” New England Journal of Medicine. 329(5):321-325, July 29, 1993.

Fuchs, Victor. 1998. "Health Care for the Elderly: How much? Who Will Pay for It?" NBER Working Paper 6755.

Garber, Alan M. and Charles E. Phelps, "Economic foundations of cost-effectiveness analysis", Journal of Health Economics, 1997:1, 1-31.

Goldman, Lee, and Cook E. Fran, "The decline in ischemic heart disease mortality rates. An analysis of the comparative effects of medical interventions and changes in lifestyle", Annals of Internal Medicine. 101(6):825-36, December 1984. 
Hoffman, Catherine, Dorothy Rice, and Hai-Yen Sung, "Persons With Chronic Conditions: Their Prevalence and Costs", Journal of the American Medical Association, 276(18):1473-1479, November 13, 1996.

Hunink, Maria G.M., et. al. 1997. "The Recent Decline in Mortality from Coronoary Heart Disease, 1980-1990: The Effect of Secular Trends in Risk Factors and Treatment." Journal of the American Medical Association 227(7): 535-542.

Lakdawalla, Darius and Tomas Philipson, "The Rise in Old Age Longevity and the Market for Long-Term Care” NBER Working Paper 6547, May 1998.

Lubitz, James D., and Gerald F. Riley. 1993. "Trends in Medicare Payments in the Last Year of Life." New England Journal of Medicine 328:1092-1096, April 15, 1993.

Lubitz, James, James Beebe, and Colin Baker, "Longevity and Medicare Expenditures", New England Journal of Medicine. 332(15):999-1003, April 13, 1995.

Manton, Kenneth, Larry S. Corder, and Eric Stallard. 1997. "Chronic disability trends in elderly United States population: 1982-1994" Proceedings of the National Academy of Sciences, 94:2593-8.

McKeown, Thomas, The Modern Rise of Population, New York: Academic Press, 1976.

Meltzer, David, "Accounting for future costs in medical cost-effectiveness", Journal of Health Economics, 1997:1, 33-64.

Poterba, James and Lawrence Summers, "Public Policy Implications of Declining Old Age Mortality", in Gary Burtless, ed., Work, Health, and Income Among the Elderly, Washington, D.C.: The Brookings Institution, 1982.

Preston, Sam, “American Longevity: Past, Present, and Future", Syracuse University Center for Economic Policy Research Policy Brief, 1996.

Sempos, C., R. Cooper, MG. Kovar, and M. McMillen, "Divergence of the recent trends in coronary 
mortality for the four major race-sex groups in the United States" American Journal of Public Health, 78(11):1422-7, November 1988.

Sytkowski, PA, Kannel WB, and D'Agostino RB, "Changes in risk factors and the decline in mortality from cardiovascular disease. The Framingham Heart Study", New England Journal of Medicine. 322(23):1635-41, June 7, 1990.

Thomas, Lewis, "The Lives of a Cell: Notes of a Biology Watcher", Toronto: Bantam Books, 1975.

Vita, AJ, Terry RB, Hubert HB, Fires JF. 1998. Aging, Health Risks, and Cumulative Disability, New England Journal of Medicine 228:1035-1041.

Waidmann, Timothy, John Bound, and Michael Schoenbaum. 1995. "The Illusion of Failure: Trends in the Self-Reported Health of the U.S. Elderly", The Milbank Quarterly, 253-287. 
Table 1: Forecast Changes in Demographics and Medical Spending

\begin{tabular}{|c|c|c|c|c|c|c|}
\hline \multirow[b]{3}{*}{ Age } & \multicolumn{4}{|c|}{ Population Distribution by Age } & \multicolumn{2}{|c|}{$\begin{array}{c}\text { Medical Spending by } \\
\text { Age, } 1987\end{array}$} \\
\hline & \multirow[b]{2}{*}{1990} & \multicolumn{3}{|c|}{ Projection to 2050} & \multirow[b]{2}{*}{ Total } & \multirow[b]{2}{*}{ Public } \\
\hline & & Low & $\begin{array}{l}\text { Inter- } \\
\text { mediate }\end{array}$ & High & & \\
\hline$<20$ & $28.9 \%$ & $27.3 \%$ & $23.2 \%$ & $18.9 \%$ & $\$ 745$ & $\$ 198$ \\
\hline $20-64$ & $58.8 \%$ & $55.6 \%$ & $55.6 \%$ & $55.8 \%$ & 1,535 & 395 \\
\hline $65+$ & $12.3 \%$ & $17.0 \%$ & $20.8 \%$ & $25.3 \%$ & 5,360 & 3,356 \\
\hline $65-69$ & $4.0 \%$ & $4.8 \%$ & $5.4 \%$ & $6.0 \%$ & 3,728 & 2,298 \\
\hline $70-74$ & $3.1 \%$ & $3.9 \%$ & $4.4 \%$ & $5.1 \%$ & 4,424 & 2,860 \\
\hline $75-79$ & $2.4 \%$ & $3.2 \%$ & $3.8 \%$ & $4.5 \%$ & 5,455 & 3,612 \\
\hline $80-84$ & $1.5 \%$ & $2.5 \%$ & $3.1 \%$ & $3.9 \%$ & 6,717 & 4,384 \\
\hline $85+$ & $1.3 \%$ & $2.7 \%$ & $4.0 \%$ & $5.8 \%$ & 9,178 & 5,547 \\
\hline $\begin{array}{l}\text { Note: } \mathrm{P} \\
\text { spendin }\end{array}$ & $\begin{array}{l}\text { forecas } \\
\text { s are at }\end{array}$ & $\begin{array}{l}\text { re from } \\
\text { rs'calcu }\end{array}$ & $\begin{array}{l}\text { Social S } \\
\text { tions. }\end{array}$ & urity A & tration & dical \\
\hline
\end{tabular}


Table 2: The Share of "Marginal Survivors"

Percent in Age Group Alive in 1990 Who Would Have Been Dead Under Mortality Rates of Indicated Year

\begin{tabular}{lcccc}
\cline { 2 - 5 } Mortality Structure in: & $65+$ & $65-74$ & $75-84$ & $85+$ \\
\hline 1960 & $23 \%$ & $14 \%$ & $25 \%$ & $49 \%$ \\
1970 & 18 & 12 & 20 & 35 \\
1980 & 6 & 4 & 7 & 12 \\
\hline
\end{tabular}

Note: Based on Social Security Life Tables. 
Table 3: Percent of Elderly in Last Year of Life

\begin{tabular}{lccccc}
\hline Age & 1990 & 2010 & 2030 & 2050 & 2070 \\
\hline $65+$ & $5.0 \%$ & $5.0 \%$ & $4.2 \%$ & $4.7 \%$ & $4.4 \%$ \\
$65-69$ & 2.3 & 2.0 & 1.8 & 1.7 & 1.5 \\
$70-74$ & 3.3 & 3.0 & 2.7 & 2.5 & 2.3 \\
$75-79$ & 5.0 & 4.6 & 4.1 & 3.8 & 3.5 \\
$80-84$ & 7.6 & 6.9 & 6.2 & 5.7 & 5.2 \\
$85-89$ & 11.5 & 10.6 & 9.5 & 8.7 & 7.9 \\
$90-94$ & 17.5 & 16.2 & 14.5 & 13.2 & 12.0 \\
$95+$ & 27.0 & 25.3 & 23.1 & 20.2 & 19.3 \\
Average Age & & & & \\
at Death & 79.5 & 81.1 & 80.1 & 83.1 & 83.5 \\
\hline Note: Data based on Social Security life tables. \\
\hline \hline \multicolumn{7}{l}{}
\end{tabular}


Table 4: Restricted Activity Days Among the Elderly

\begin{tabular}{|c|c|c|c|c|c|c|}
\hline Age & 1970 & 1975 & 1980 & 1985 & 1990 & 1995 \\
\hline \multicolumn{7}{|c|}{ Restricted Activity Days (past year) } \\
\hline $65+$ & 33.1 & 39.2 & 40.7 & 32.4 & 32.3 & 33.2 \\
\hline $65-74$ & 29.2 & 35.9 & 37.0 & 29.2 & 27.5 & 29.4 \\
\hline $75-84$ & 37.7 & 43.1 & 45.1 & 36.0 & 37.2 & 37.3 \\
\hline $85+$ & 45.0 & 48.6 & 51.4 & 43.6 & 50.1 & 46.8 \\
\hline \multicolumn{7}{|c|}{ Bed Days (past year) } \\
\hline $65+$ & 13.7 & 14.4 & 14.1 & 14.7 & 14.2 & 13.5 \\
\hline $65-74$ & 11.1 & 12.3 & 11.8 & 12.2 & 11.4 & 11.3 \\
\hline $75-84$ & 15.4 & 16.1 & 15.8 & 16.5 & 16.3 & 15.5 \\
\hline $85+$ & 26.2 & 23.3 & 24.5 & 26.7 & 27.3 & 22.8 \\
\hline \multicolumn{7}{|c|}{$\begin{array}{l}\text { Note: Data are based on the National Health Interview Survey. Survey years } \\
\text { are a three year window around the indicated year (for example, 1969-71 for } \\
\text { 1970) except for } 1995 \text {, which uses data from 1993-95. }\end{array}$} \\
\hline
\end{tabular}


Table 5: Ability to Perform Major Activity for the Elderly

\begin{tabular}{|c|c|c|c|}
\hline & 1985 & 1990 & 1995 \\
\hline \multicolumn{4}{|l|}{ Ages 65+ } \\
\hline Unable to perform major activity & $10.6 \%$ & $10.3 \%$ & $10.4 \%$ \\
\hline Limited in kind/amount of major activity & 13.2 & 12.1 & 12.0 \\
\hline Limited in other activities & 15.4 & 15.5 & 15.6 \\
\hline Not limited & 60.7 & 62.1 & 62.1 \\
\hline \multicolumn{4}{|l|}{ Ages $65-74$} \\
\hline Unable to perform major activity & $10.9 \%$ & $10.4 \%$ & $10.8 \%$ \\
\hline Limited in kind/amount of major activity & 11.4 & 10.2 & 9.9 \\
\hline Limited in other activities & 14.0 & 13.5 & 13.3 \\
\hline Not limited & 63.7 & 65.9 & 66.0 \\
\hline \multicolumn{4}{|l|}{ Ages $75-84$} \\
\hline Unable to perform major activity & $7.8 \%$ & $7.8 \%$ & $7.6 \%$ \\
\hline Limited in kind/amount of major activity & 14.0 & 13.1 & 12.8 \\
\hline Limited in other activities & 18.6 & 19.6 & 19.9 \\
\hline Not limited & 59.6 & 59.5 & 59.7 \\
\hline \multicolumn{4}{|l|}{ Ages $85+$} \\
\hline Unable to perform major activity & $19.6 \%$ & $19.6 \%$ & $18.7 \%$ \\
\hline Limited in kind/amount of major activity & 24.6 & 22.9 & 24.4 \\
\hline Limited in other activities & 13.6 & 14.0 & 15.6 \\
\hline Not limited & 42.2 & 43.5 & 41.3 \\
\hline \multicolumn{4}{|c|}{$\begin{array}{l}\text { Note: Major activity is defined as one of the following: working; keeping } \\
\text { house; school; something else; unknown. Data are from the National Health } \\
\text { Interview Survey. }\end{array}$} \\
\hline
\end{tabular}


Table 6: Self-Reported Health Status of the Elderly

\begin{tabular}{|c|c|c|c|c|c|}
\hline & 1975 & 1980 & 1985 & 1990 & 1995 \\
\hline \multicolumn{6}{|l|}{ Ages 65+ } \\
\hline Excellent & $28.6 \%$ & $28.8 \%$ & $16.0 \%$ & $16.4 \%$ & $15.8 \%$ \\
\hline Very Good & - & --- & 20.5 & 22.9 & 22.9 \\
\hline Good & 39.4 & 40.1 & 32.3 & 32.2 & 33.3 \\
\hline Fair & 22.8 & 22.4 & 20.9 & 19.1 & 19.0 \\
\hline Poor & 9.3 & 8.6 & 10.4 & 9.3 & 8.9 \\
\hline \multicolumn{6}{|l|}{ Ages 65-74 } \\
\hline Excellent & $29.0 \%$ & $29.0 \%$ & $17.0 \%$ & $18.0 \%$ & $17.0 \%$ \\
\hline Very Good & --- & -- & 20.9 & 24.0 & 23.8 \\
\hline Good & 41.0 & 40.3 & 32.8 & 32.3 & 33.2 \\
\hline Fair & 21.7 & 22.8 & 20.2 & 17.7 & 18.0 \\
\hline Poor & 8.2 & 8.1 & 9.2 & 8.1 & 7.9 \\
\hline \multicolumn{6}{|l|}{ Ages 75-84 } \\
\hline Excellent & $28.0 \%$ & $29.0 \%$ & $15.0 \%$ & $14.0 \%$ & $14.0 \%$ \\
\hline Very Good & --- & --- & 19.6 & 21.5 & 21.7 \\
\hline Good & 40.0 & 39.8 & 31.9 & 32.6 & 33.6 \\
\hline Fair & 22.5 & 22.6 & 22.0 & 21.2 & 20.6 \\
\hline Poor & 9.6 & 9.0 & 12.0 & 10.5 & 10.3 \\
\hline \multicolumn{6}{|l|}{ Ages 85+ } \\
\hline Excellent & $32.0 \%$ & $30.0 \%$ & $16.0 \%$ & $14.0 \%$ & $13.0 \%$ \\
\hline Very Good & --- & --- & 20.4 & 20.1 & 19.7 \\
\hline Good & 39.9 & 39.9 & 29.6 & 30.6 & 32.1 \\
\hline Fair & 18.7 & 19.2 & 21.4 & 21.1 & 22.5 \\
\hline Poor & 9.7 & 11.3 & 12.9 & 14.0 & 12.7 \\
\hline
\end{tabular}


Table 7: Disability Rates Among the Elderly

\begin{tabular}{lcccc}
\hline & \multicolumn{4}{c}{ Disability Rate in Year: } \\
\cline { 2 - 5 } Age and Extent & 1982 & 1984 & 1989 & 1994 \\
\hline All Ages & $24.9 \%$ & $24.9 \%$ & $23.3 \%$ & $21.3 \%$ \\
IADLs & 5.6 & 6.0 & 4.7 & 4.3 \\
1-2 ADLs & 6.6 & 6.7 & 6.5 & 5.9 \\
3-4 ADLs & 2.9 & 3.0 & 3.6 & 3.2 \\
5-6 ADLs & 3.6 & 3.3 & 2.8 & 2.8 \\
Institutionalized & 6.3 & 6.1 & 5.7 & 5.2 \\
& & & & \\
By Age & $13.8 \%$ & $13.0 \%$ & $11.8 \%$ & $10.9 \%$ \\
65-74 & 29.1 & 29.4 & 27.9 & 24.1 \\
75-84 & 61.9 & 63.9 & 59.8 & 56.6 \\
85+ & \multicolumn{5}{l}{} \\
\hline Note: Data are from the National Long-Term Care Survey \\
\hline \hline
\end{tabular}


Table 8: Disability Changes for the Elderly in OECD Countries

\begin{tabular}{|c|c|c|c|c|c|c|c|}
\hline \multirow[b]{3}{*}{ Country } & \multirow[b]{3}{*}{ Years } & \multicolumn{3}{|c|}{ Serious Disability Rate } & \multicolumn{3}{|c|}{ Institutionalization Rate } \\
\hline & & & & Annual & & & Annual \\
\hline & & Year 1 & Year 2 & Change & Year 1 & Year 2 & Change \\
\hline US & 1982,94 & $13.3 \%$ & $12.4 \%$ & $-0.6 \%$ & $5.7 \%$ & $5.1 \%$ & $-0.9 \%$ \\
\hline Australia & 1985,96 & 17.0 & 17.3 & 0.2 & 6.7 & 6.5 & -0.3 \\
\hline Canada & 1985,91 & 9.3 & 10.4 & 1.9 & 7.8 & 7.6 & -0.4 \\
\hline France & 1990,94 & 3.2 & 2.4 & -7.2 & 6.3 & 6.5 & 0.8 \\
\hline Germany & 1986,95 & 25.0 & 19.5 & -2.8 & --- & --- & --- \\
\hline Japan & 1989,96 & 10.3 & 8.8 & -2.2 & 7.5 & 5.1 & -5.5 \\
\hline Sweden & 1975,95 & 22.0 & 18.0 & -1.0 & --- & --- & -- \\
\hline UK & 1980,94 & 8.8 & 8.7 & -0.1 & --- & --- & --- \\
\hline
\end{tabular}


Table 9: Medicare Expenditure in Last Year of

\begin{tabular}{lcc}
\multicolumn{3}{c}{ Life, 1988 } \\
\hline \multirow{2}{*}{ Age At Death } & \multicolumn{2}{c}{ Medicare Spending } \\
\cline { 2 - 3 } $65-69$ & Survivors & Decedents \\
$70-74$ & 1,845 & $\$ 15,436$ \\
$75-79$ & 2,176 & 15,778 \\
$80-84$ & 2,403 & 14,902 \\
$85-89$ & 2.578 & 12,838 \\
$90+$ & 2,258 & 8,888 \\
\hline Note: Based on Lubitz and Riley (1993). \\
\hline \hline
\end{tabular}


Table 10: Annual Growth Rate of Real Medicare Spending by Age

\begin{tabular}{lccccc}
\hline Age & $67-77$ & $77-82$ & $82-87$ & $87-92$ & $92-95$ \\
\hline $65-66$ & $7.8 \%$ & $5.3 \%$ & $3.5 \%$ & $2.9 \%$ & $3.0 \%$ \\
$67-68$ & 6.9 & 6.3 & 3.3 & 3.7 & 3.6 \\
$69-70$ & 7.0 & 6.5 & 4.1 & 3.4 & 3.6 \\
$71-72$ & 6.7 & 7.1 & 4.9 & 2.9 & 3.5 \\
$73-74$ & 7.1 & 6.6 & 4.7 & 3.6 & 3.6 \\
$75-79$ & 6.6 & 6.8 & 4.5 & 4.3 & 3.3 \\
$80-84$ & 6.0 & 7.1 & 3.8 & 4.3 & 6.4 \\
$85+$ & 5.5 & 6.4 & 3.9 & 4.8 & 7.4 \\
& & & & \\
Average & $6.8 \%$ & $6.7 \%$ & $4.2 \%$ & $4.1 \%$ & $4.9 \%$ \\
\hline \multicolumn{5}{l}{ Note: Data are based on Medicare program statistics. } \\
\hline \hline
\end{tabular}

Table 11: Forecasts of Medicare Acute Care Expenditures, Accounting for Changes in Age at Death, Disability among Survivors, and Increasing Per Person Medical Costs

\begin{tabular}{lccccc}
\hline Simulation & 1992 & 2010 & 2030 & 2050 & 2070 \\
\hline \multicolumn{7}{l}{ Forecast Holding Constant } & Age-Specific Spending \\
All & $\$ 3,232$ & $\$ 3,342$ & $\$ 3,272$ & $\$ 3,510$ & $\$ 3,518$ \\
& {$[1.00]$} & {$[1.03]$} & {$[1.01]$} & {$[1.09]$} & {$[1.09]$}
\end{tabular}


Forecast Accounting for Change in Age of Death

$\begin{array}{cccccc}\text { All } & \$ 3,232 & \$ 3,261 & \$ 3,121 & \$ 3,287 & \$ 3,240 \\ & {[1.00]} & {[1.01]} & {[.97]} & {[1.02]} & {[1.00]}\end{array}$

Forecast Accounting for Change in Age of Death and Allowing for Reduction in Disability Among Survivors

$1 \%$ annual reduction

\begin{tabular}{ccccc}
$\$ 3,234$ & $\$ 3,138$ & $\$ 2,903$ & $\$ 2,947$ & $\$ 2,825$ \\
{$[1.00]$} & {$[.97]$} & {$[.90]$} & {$[.91]$} & {$[.87]$} \\
$\$ 3,234$ & $\$ 3,083$ & $\$ 2,822$ & $\$ 2,838$ & $\$ 2,713$ \\
{$[1.00]$} & {$[.95]$} & {$[.87]$} & {$[.88]$} & {$[.84]$} \\
\hline
\end{tabular}

Medicare Spending on the Aged as a Share of GDP

Medicare costs grow with GDP per capita

$\begin{array}{llllll}\text { Holding Constant Age- } & 1.7 \% & 1.8 \% & 2.7 \% & 3.1 \% & 3.3 \%\end{array}$

Specific Spending

$\begin{array}{llllll}\text { Accounting for Change in } \quad 1.7 \% & 1.7 \% & 2.4 \% & 2.5 \% & 2.6 \%\end{array}$

Age of Death and 1\%

Reduction in Disability

Medicare costs grow at historic rate of increase relative to GDP

$\begin{array}{llllll}\text { Holding Constant Age- } & 1.7 \% & 2.9 \% & 7.1 \% & 12.8 \% & 22.3 \%\end{array}$

Specific Spending

$\begin{array}{llllll}\text { Accounting for Change in } \quad 1.7 \% & 2.7 \% \quad 6.1 \% \quad 10.4 \% \quad 17.2 \%\end{array}$

Age of Death and 1\%

Reduction in Disability

Note: The numbers in [.] are the ratio to spending in 1992. 
Table 12: Effect of Disability on Medicare Expenditures

\begin{tabular}{|c|c|c|}
\hline Independent Variable & (1) & (2) \\
\hline \multirow[t]{2}{*}{ Constant } & 1848 & 1357 \\
\hline & (159) & $(163)$ \\
\hline \multirow[t]{2}{*}{$70-74$} & 351 & 360 \\
\hline & $(217)$ & $(215)$ \\
\hline \multirow[t]{2}{*}{$75-79$} & 698 & 560 \\
\hline & $(236)$ & (234) \\
\hline \multirow[t]{2}{*}{$80-84$} & 1200 & 711 \\
\hline & $(270)$ & $(271)$ \\
\hline \multirow[t]{2}{*}{$85+$} & 1736 & 612 \\
\hline & $(312)$ & $(434)$ \\
\hline \multirow[t]{2}{*}{ Number IADLS } & -- & 252 \\
\hline & & (69) \\
\hline \multirow[t]{2}{*}{ Number ADLs } & --- & 490 \\
\hline & & $(86)$ \\
\hline $\mathrm{N}$ & 6913 & 6913 \\
\hline $\mathrm{R}^{2}$ & .006 & .03 \\
\hline
\end{tabular}

Note: Regressions use data from the Medicare Current Beneficiary Survey. 
Table 13: Probability of Nursing Home Use

\begin{tabular}{|c|c|c|c|c|c|c|c|c|}
\hline \multirow[b]{2}{*}{ Variable } & \multicolumn{4}{|c|}{ Men } & \multicolumn{4}{|c|}{ Women } \\
\hline & (1) & (2) & (3) & (4) & (5) & (6) & (7) & (8) \\
\hline \multirow[t]{2}{*}{ Constant } & 1.02 & -0.12 & -2.96 & -3.07 & .83 & -.62 & -4.42 & -4.39 \\
\hline & (.69) & $(.60)$ & $(.55)$ & $(.54)$ & $(.72)$ & $(.78)$ & $(.70)$ & $(.70)$ \\
\hline \multirow[t]{2}{*}{$70-74$} & .49 & .71 & .55 & .49 & .89 & .77 & .84 & .70 \\
\hline & $(.82)$ & $(.80)$ & $(.71)$ & $(.71)$ & $(.97)$ & $(.97)$ & $(.84)$ & (.84) \\
\hline \multirow[t]{2}{*}{$75-79$} & 2.13 & 2.08 & 1.01 & .79 & 2.72 & 2.20 & .78 & .41 \\
\hline & $(.91)$ & $(.89)$ & $(.79)$ & $(.79)$ & $(1.02)$ & $(1.03)$ & $(.90)$ & $(.90)$ \\
\hline \multirow[t]{2}{*}{$80-84$} & 6.43 & 6.46 & 2.91 & 2.53 & 9.62 & 8.61 & 4.45 & 4.01 \\
\hline & $(1.07)$ & (1.04) & $(.94)$ & $(.95)$ & $(1.12)$ & $(1.16)$ & $(1.02)$ & $(1.02)$ \\
\hline \multirow[t]{2}{*}{$85+$} & 10.39 & 5.02 & -2.61 & -3.18 & 26.35 & 17.45 & -5.49 & -6.05 \\
\hline & $(1.29)$ & $(1.61)$ & (1.66) & (1.66) & $(1.17)$ & $(3.19)$ & $(2.91)$ & (2.89) \\
\hline \multirow[t]{2}{*}{ Divorced } & -- & 1.49 & .62 & 0.63 & --- & 2.83 & .38 & .48 \\
\hline & & $(1.58)$ & $(1.1)$ & (1.13) & & $(1.45)$ & $(1.27)$ & $(1.26)$ \\
\hline \multirow{2}{*}{$\begin{array}{c}\text { Divorced* } \\
\text { Age85+ }\end{array}$} & --- & 8.84 & 15.28 & 1.59 & --- & .73 & -.23 & -.62 \\
\hline & & $(2.53)$ & $(5.46)$ & $(5.45)$ & & $(6.01)$ & $(5.24)$ & $(5.21)$ \\
\hline \multirow[t]{2}{*}{ Widowed } & --- & 2.74 & .15 & .03 & --. & 2.70 & 1.30 & 1.15 \\
\hline & & $(1.26)$ & $(.88)$ & $(.87)$ & & $(.80)$ & $(.70)$ & $(.70)$ \\
\hline \multirow{4}{*}{$\begin{array}{l}\text { Widowed* } \\
\text { Age } 85+ \\
\text { Never Married }\end{array}$} & --- & 17.35 & 3.89 & 3.67 & --- & 8.15 & .77 & .47 \\
\hline & & (6.08) & $(2.31)$ & $(2.31)$ & & $(3.35)$ & $(2.93)$ & (2.91) \\
\hline & --- & 14.98 & 12.55 & 12.56 & --- & 7.19 & 6.12 & 5.97 \\
\hline & & (1.58) & $(1.42)$ & $(1.42)$ & & $(1.78)$ & $(1.55)$ & (1.54) \\
\hline \multirow{2}{*}{$\begin{array}{l}\text { Never Married* } \\
\text { Age85 }\end{array}$} & --- & 26.0 & 19.07 & 19.23 & --- & 13.45 & 3.15 & 2.82 \\
\hline & & $(5.93)$ & $(5.35)$ & $(5.33)$ & & $(5.12)$ & $(4.48)$ & $(4.45)$ \\
\hline \multirow[t]{2}{*}{ ADLS } & --- & -- & 1.62 & 1.60 & --- & -- & 1.69 & 1.54 \\
\hline & & & $(.33)$ & (.33) & & & $(.33)$ & $(.33)$ \\
\hline \multirow[t]{2}{*}{ ADLS*Age $85+$} & --- & --- & 1.79 & 1.68 & --- & --- & 2.35 & 2.28 \\
\hline & & & $(.90)$ & $(.90)$ & & & $(.67)$ & $(.67)$ \\
\hline \multirow[t]{2}{*}{ IADLS } & --- & --- & 3.52 & 3.37 & --- & --- & 3.19 & 3.05 \\
\hline & & & $(.27)$ & $(.27)$ & & & $(.27)$ & $(.27)$ \\
\hline \multirow[t]{2}{*}{ IADLS*Age $85+$} & --- & --- & -.19 & -.11 & --- & --- & 4.17 & 4.09 \\
\hline & & & $(.72)$ & $(.72)$ & & & $(.57)$ & $(.56)$ \\
\hline Within 1 Year of & --- & --- & --- & 4.14 & --- & -- & --- & 8.18 \\
\hline Death & & & & $(.92)$ & & & & $(1.05)$ \\
\hline $\mathrm{N}$ & 3040 & 3037 & 3037 & 3037 & 4839 & 4828 & 4828 & 4828 \\
\hline $\mathrm{R}^{2}$ & .03 & .08 & .26 & .26 & .12 & .13 & .4 & .4 \\
\hline
\end{tabular}


Table 14: Forecasts of Nursing Home Utilization,

Accounting for Age at Death, Disability, and Changes in Demographics

\begin{tabular}{|c|c|c|c|c|c|}
\hline \multirow[b]{2}{*}{ Simulation } & \multicolumn{5}{|c|}{ Year } \\
\hline & 1990 & 2010 & 2030 & 2050 & 2070 \\
\hline \multicolumn{6}{|c|}{ Forecast Holding Constant Age and Sex Specific Utilization } \\
\hline Nursing home utilization rate & $\begin{array}{l}5.2 \% \\
{[1.00]}\end{array}$ & $\begin{array}{l}6.1 \% \\
{[1.17]}\end{array}$ & $\begin{array}{l}5.3 \% \\
{[1.02]}\end{array}$ & $\begin{array}{c}7.2 \% \\
{[1.39]}\end{array}$ & $\begin{array}{l}7.1 \% \\
{[1.36]}\end{array}$ \\
\hline Share of GDP accounted for & $1.0 \%$ & $1.4 \%$ & $2.1 \%$ & $3.2 \%$ & $3.5 \%$ \\
\hline \multicolumn{6}{|c|}{ Forecast Holding Constant Age, Sex and Marital Status Specific Utilization } \\
\hline Nursing home utilization rate & $\begin{array}{l}5.2 \% \\
{[1.00]}\end{array}$ & $\begin{array}{l}5.9 \% \\
{[1.13]}\end{array}$ & $\begin{array}{l}5.5 \% \\
{[1.05]}\end{array}$ & $\begin{array}{l}7.6 \% \\
{[1.46]}\end{array}$ & $\begin{array}{l}7.7 \% \\
{[1.47]}\end{array}$ \\
\hline Share of GDP accounted for & $1.0 \%$ & $1.4 \%$ & $2.2 \%$ & $3.3 \%$ & $3.8 \%$ \\
\hline \multicolumn{6}{|c|}{$\begin{array}{l}\text { Forecast Holding Constant Age, Sex and Marital Status Specific Utilization, } \\
\text { and Allowing for } 1 \text { Percent Annual Reduction in Disability Rate over Time }\end{array}$} \\
\hline Nursing home utilization rate & $\begin{array}{l}5.2 \% \\
{[1.00]}\end{array}$ & $\begin{array}{l}4.5 \% \\
{[.87]}\end{array}$ & $\begin{array}{l}3.6 \% \\
{[.68]}\end{array}$ & $\begin{array}{l}4.1 \% \\
{[.78]}\end{array}$ & $\begin{array}{l}3.4 \% \\
{[.65]}\end{array}$ \\
\hline Share of GDP accounted for & $1.0 \%$ & $1.0 \%$ & $1.4 \%$ & $1.8 \%$ & $1.7 \%$ \\
\hline \multicolumn{6}{|c|}{$\begin{array}{l}\text { Forecast Holding Constant Age, Sex and Marital Status Specific Utilization, } \\
\text { and Allowing for Changes in Disability over Time and Changes in Time Until Death }\end{array}$} \\
\hline Nursing home utilization rate & $\begin{array}{l}5.2 \% \\
{[1.00]}\end{array}$ & $\begin{array}{l}4.3 \% \\
{[.83]}\end{array}$ & $\begin{array}{l}2.8 \% \\
{[.55]}\end{array}$ & $\begin{array}{l}3.3 \% \\
{[.63]}\end{array}$ & $\begin{array}{l}2.5 \% \\
{[.48]}\end{array}$ \\
\hline Share of GDP accounted for & $1.0 \%$ & $1.0 \%$ & $1.1 \%$ & $1.4 \%$ & $1.2 \%$ \\
\hline \multicolumn{6}{|c|}{$\begin{array}{l}\text { Forecast Holding Constant Age, Sex and Marital Status Specific Utilization, } \\
\text { Allowing for Changes in Disability and Time Until Death, } \\
\text { and Growth of Nursing Home Costs at } 4 \text { Percent per Year }\end{array}$} \\
\hline Share of GDP accounted for & $1.0 \%$ & $1.7 \%$ & $3.3 \%$ & $7.3 \%$ & $10.9 \%$ \\
\hline
\end{tabular}


Table 15: Marital Status of Elderly Population

\begin{tabular}{|c|c|c|c|c|c|}
\hline Marital Status & 1990 & 2010 & 2030 & 2050 & 2070 \\
\hline \multicolumn{6}{|l|}{ Males, $65+$} \\
\hline$\%$ Married & $74.1 \%$ & $73.0 \%$ & $68.9 \%$ & $65.9 \%$ & $65.5 \%$ \\
\hline$\%$ Widowed & 15.4 & 14.9 & 13.0 & 13.6 & 12.7 \\
\hline$\%$ Divorced & 5.0 & 7.3 & 9.5 & 8.5 & 8.5 \\
\hline$\%$ Never Married & 5.5 & 4.8 & 8.6 & 11.9 & 13.3 \\
\hline \multicolumn{6}{|l|}{ Males $85+$} \\
\hline$\%$ Married & $45.5 \%$ & $54.2 \%$ & $55.3 \%$ & $51.4 \%$ & $52.7 \%$ \\
\hline$\%$ Widowed & 46.5 & 38.5 & 35.6 & 34.0 & 31.9 \\
\hline$\%$ Divorced & 2.8 & 4.7 & 6.7 & 8.5 & 7.9 \\
\hline \% Never Married & 5.2 & 2.6 & 2.4 & 6.0 & 7.6 \\
\hline \multicolumn{6}{|l|}{ Females 65+ } \\
\hline$\%$ Married & $39.7 \%$ & $41.4 \%$ & $44.8 \%$ & $41.9 \%$ & $43.5 \%$ \\
\hline$\%$ Widowed & 50.6 & 45.1 & 34.2 & 35.8 & 33.7 \\
\hline$\%$ Divorced & 4.2 & 9.1 & 14.9 & 13.8 & 13.4 \\
\hline$\%$ Never Married & 5.5 & 4.4 & 6.1 & 8.5 & 9.4 \\
\hline \multicolumn{6}{|l|}{ Females $85+$} \\
\hline$\%$ Married & $13.4 \%$ & $13.3 \%$ & $15.4 \%$ & $17.1 \%$ & $17.9 \%$ \\
\hline \% Widowed & 77.1 & 77.4 & 70.0 & 62.1 & 60.5 \\
\hline$\%$ Divorced & 3.0 & 4.6 & 10.8 & 14.8 & 13.5 \\
\hline$\%$ Never Married & 6.5 & 4.7 & 3.8 & 6.0 & 8.1 \\
\hline
\end{tabular}




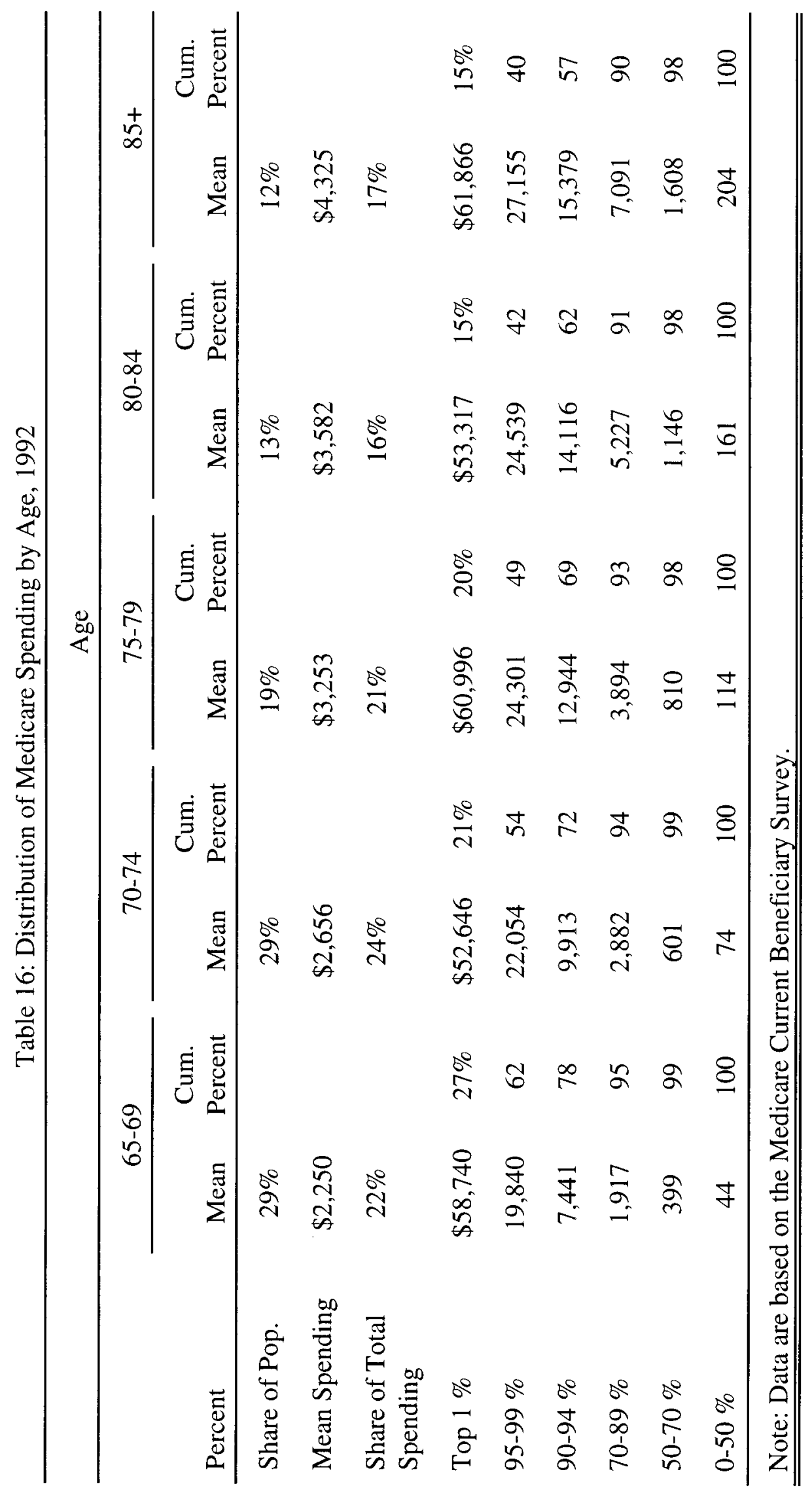

